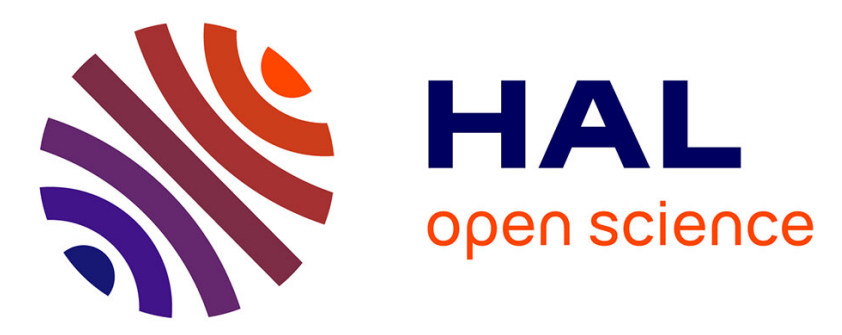

\title{
Constitutive modelling of cohesionless soils and interfaces with various internal states: An elasto-plastic approach
}

Jérôme Duriez, É. Vincens

\section{- To cite this version:}

Jérôme Duriez, É. Vincens. Constitutive modelling of cohesionless soils and interfaces with various internal states: An elasto-plastic approach. Computers and Geotechnics, 2015, 63, pp.33 - 45. 10.1016/j.compgeo.2014.08.001 . hal-01865383

\section{HAL Id: hal-01865383 \\ https://hal.science/hal-01865383}

Submitted on 31 Aug 2018

HAL is a multi-disciplinary open access archive for the deposit and dissemination of scientific research documents, whether they are published or not. The documents may come from teaching and research institutions in France or abroad, or from public or private research centers.
L'archive ouverte pluridisciplinaire HAL, est destinée au dépôt et à la diffusion de documents scientifiques de niveau recherche, publiés ou non, émanant des établissements d'enseignement et de recherche français ou étrangers, des laboratoires publics ou privés. 


\title{
Constitutive modelling of cohesionless soils and interfaces with various internal states: an elasto-plastic approach
}

\author{
J. Duriez ${ }^{\mathrm{a}, \mathrm{b}, *}$, É. Vincens $^{\mathrm{a}}$ \\ ${ }^{a}$ LTDS, Université de Lyon, UMR CNRS 5513, École Centrale de Lyon, Écully, France \\ ${ }^{b}$ Univ. Grenoble Alpes, $3 S R, F-38000$ Grenoble, France \\ CNRS, 3SR, F-38000 Grenoble, France
}

\begin{abstract}
A discussion is led on a constitutive modelling of granular soils and soil-structure interfaces for which large changes in their internal state are likely to take place throughout loading. Relevant variables accounting for this internal state are discussed. They must include the effects of both the specific volume and the mean pressure and also the influence of the contact directions of the granular assembly related to induced anisotropy in the granular material. Two elastoplastic constitutive models for the volume element of soil and for soil-structure interfaces are presented. They were designed in such a way that with a unique set of model parameters, very different internal states can be addressed throughout cyclic loadings. The validation of the constitutive models was performed on the basis of experimental tests performed using Fontainebleau sand. Finally, the validation is achieved studying a boundary value problem involving cyclic axially loadings on a pile located in a sand massif. The simulations showed results in a fairly good agreement with the results obtained from corresponding centrifuge tests confirming the predictive capability of the two constitutive models.
\end{abstract}

Keywords: elasto-plasticity, critical state mechanics, cyclic loading, soil-pile interaction, granular soils

Complex loading paths such as cyclic loadings are handled by the constitutive models of soils with difficulty. The problem arises from the extensive changes in the internal structure of the material during such loading paths. Generally, the constitutive models give fair prediction of the soil behaviour when the initial state and the loading path are not too far from those used for the identification of the model constants. When the loading path has induced great changes in the internal structure, the set of parameters is no more adapted to the actual material properties of the material. Such cyclic loadings are nevertheless typical in civil engineering. We can cite the dynamical forces induced by earthquakes but also the repeated actions of wind and wind waves on off-shore energy pro-

\footnotetext{
*Corresponding author
} 
duction plants. Similar loading affects eolian in-shore power plants and their soil foundation.

If great changes take place within the granular material, it is therefore important that the associated constitutive model reflects these changes in a certain way. The first part of this work is thus dedicated to the definition of appropriate variables that could be introduced in a constitutive model for soil in order to better take into account the great evolution of the internal structure.

First, concerning the constitutive modelling itself, decades of scientific work took place since the first adaptations of elasto-plasticity to soils by Lade for example in the case of granular material [1]. Because mechanical deformations in soils are fundamentally different than those in metals, large developments have been required to better capture the behaviour of soils. The assumptions of a yield surface enclosing an elastic regime and of a plastic potential ruling plastic deformations were abandoned by different authors working outside the elasto-plasticity framework. For example, Dafalias adapted its bounding surface concept for clays [2]. This model still has in common with the classical elasto-plasticity that the compliance tensor has also two values, one for incremental stresses pointing outside the bounding surface, and another one in the other cases. More complex dependencies of the compliance tensor with respect to the incremental loading direction were also proposed. For example, incremental non-linear models were obtained assuming a direct non-linear relation between the increments of the stress tensor and of the strain tensor [3]. Other incremental non-linear (INL) models were proposed e.g. by Chambon [4] or by Darve [5] (see also, respectively, [6] and [7]) by interpolating the material response from known responses along some given loading paths. Note that the bounding surface plasticity can also lead to INL constitutive relations [8]. Such non-linear relations are generally more capable to handle complex loadings paths with changing incremental stress directions $[9,10]$.

Nevertheless, geomaterials may reveal complex behaviours on simple loading paths, such as axisymmetric ("triaxial") paths, as soon as cyclic loadings are involved. For example, the volumetric behaviour of a sand sample can drastically change during cycles if the density is sufficiently affected [11, 12, 13, 14].

Since the design of Cam-Clay model [15], the density of soils is recognized as a key parameter ruling their behaviour. In fact, the void ratio $e$ and the mean pressure $p$, though of different kinds, cannot be dissociated. Indeed, a sand that can be qualified as dense since exhibiting dilation for $p=100 \mathrm{kPa}$ can only show contractive volumetric deformations for a confining stress of 2000 $\mathrm{kPa}$ [16]. Then, one should better use the terms of contractive, poorly dilative and dilative sands which are more correct than loose, medium dense and dense sands since the nature of the behaviour also depends on the mean pressure. Figure 1 schematizes the typical behaviours of contractive and dilative sands in drained conditions. On this figure, $s_{I I} / p$ is the stress ratio, ratio between the second invariant of the stress tensor and the mean pressure, i.e. one third 
of the first invariant of the stress tensor. Different works have included the
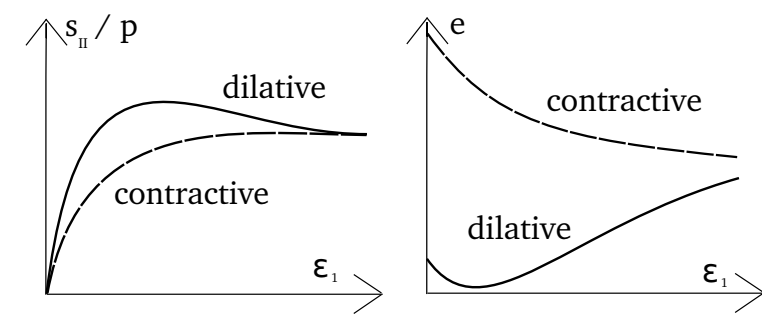

(a) Deviatoric stress varia- (b) Volumetric strain variations tions

Figure 1: Compression drained triaxial test: idealized behaviours of dilative and contractive sands.

joint influence of density and mean pressure, either in Kolymbas hypoplasticity framework [17, 18], or in bounding surface plasticity framework [19, 20], for example.

But some experiments have also revealed different features for samples with same $(e, p)$ values. In undrained experiments on Hostun sand, samples having faced different pre-loading histories show different behaviours, even if the void ratio is nearly constant for a same confining stress [21]. Similar results were also obtained for Toyoura sand [13] using drained torsional simple shear tests. Indeed, samples with a same void ratio and same confining pressure contracted very differently depending on the previous shear history. These experiments evidence the key role of the stress history and among other the key influence of the induced anisotropy created during a previous loading phase. Therefore, previously quoted works, designed for initially isotropic materials, have in this case to be improved. Different authors proposed to encompass both effects of dense state and induced anisotropy either in the classical elasto-plasticity framework $[22,23]$ or in Dafalias bounding surface plasticity $[24,25,26]$. Note that the density effects are included in the MIT-S1 model of [24] only through $e$-values, without considering $p$. However, the validation of such formulations with cyclic deviatoric loadings are not systematically presented. This is one purpose of the work presented herein. A second purpose is to present a comprehensive study, proposing both a soil and a soil-structure constitutive model, and a validation of the models through a boundary value problem.

The work in this paper is based on $C J S$ elasto-plastic model, denoted this way from the names of its authors [27, 28]. Section 1 details the general formulation of this constitutive model, comparing its main features with some classical results. Section 2 extends the discussion about variables that could describe the internal state of the soil, and details the changes that are made to CJS relations in order to take into account this internal state, as to the limits of these changes. Section 3 presents a soil-structure interface model, which is derived from the enhanced soil volume model. Finally, an application which is also a 
validation of these two models is performed solving a soil-structure problem in section 4 which is the main contribution of this work. Experimental results obtained during a benchmark which involved cyclically and axially loaded piles are compared to the blind-predictions obtained using the constitutive relations for soils and soil-structure interfaces. This benchmark was performed during the French national project SOLCYP ${ }^{1}$.

\section{Elasto-plastic relations for soils}

This section presents the general formulation of CJS model [28] (or [27, 29] in French publications) comparing its features with classical results in geomechanics. Like other constitutive models for soils, the equations describe phenomena related to the intrinsic part of the soil, i.e the solid skeleton. Therefore, if the material is saturated, stresses must be understood as effective stresses but, for convenience, the superscript ' is omitted in the following equations.

\subsection{Hypoelastic mechanism}

Inside a given stress domain (which is clearly defined in sections 1.2.2 and 1.3), incremental stresses $\boldsymbol{d} \boldsymbol{\sigma}$ are computed from incremental strains $\boldsymbol{d} \boldsymbol{\varepsilon}$ according to a non-linear Hooke's law:

$$
\begin{aligned}
\boldsymbol{d} \boldsymbol{\sigma} & =2 G^{e} \boldsymbol{d} \varepsilon+\left(K^{e}-\frac{2}{3} G^{e}\right) \operatorname{tr}(\boldsymbol{d} \varepsilon) \boldsymbol{I} \\
\Leftrightarrow \quad \boldsymbol{d} \boldsymbol{\sigma} & =K^{e} \operatorname{tr}(\boldsymbol{d} \varepsilon) \boldsymbol{I}+2 G^{e} \boldsymbol{d e}
\end{aligned}
$$

with $\boldsymbol{I}$ the identity second order tensor and $\boldsymbol{d e}$ the deviatoric part of $\boldsymbol{d} \boldsymbol{\varepsilon}$. The formulation for moduli $K^{e}$ and $G^{e}$ are given in section 2.1.

Once the limit of the hypoelastic domain is reached, irreversible strain mechanisms are initiated. Experiments on granular soils show that both deviatoric and isotropic parts of the stress tensor may lead to irreversible deformations $[30,31,13,32]$.

\subsection{Deviatoric plastic mechanism}

Additional strains, $\boldsymbol{d} \varepsilon^{d p}$, appear when the stress state reaches a given surface, the yield criterion, and at the same time when the increment of loading is directed outward. Since a precise determination of the yield surface would require complex experiments, this surface is generally stated to be similar to the plastic limit condition (also denoted failure or limit surface) that bounds the possible material stress states.

\footnotetext{
${ }^{1}$ Behaviour of piles subjected to cyclic loadings
} 


\subsubsection{Plastic limit condition}

The plastic limit condition of an initially isotropic soil depends on the three stress invariants which involve the mean pressure, the intensity of the stress deviatoric tensor and the relative magnitude of the intermediate principal stress. Different existing criteria were developed for geomaterials, for example MohrCoulomb (M-C), Matsuoka and Nakai (M-N) [33] and Lade and Duncan [1] criteria. M-N and Lade surfaces have the advantage to be differentiable without restriction, contrary to M-C surface.

The three criteria induce a direct link between failure in axisymmetric extension (with principal stresses $\sigma_{3}<\sigma_{2}=\sigma_{1}$ ) and failure in axisymmetric compression $\left(\sigma_{1}>\sigma_{2}=\sigma_{3}\right)$. M-C and M-N are identical from this point of view and are not able to predict extension failure from compression failure data correctly. Several studies involving a Discrete Element Method confirmed Lade's description of the influence of the intermediate principal stress $[34,35,36]$ and particularly the prediction of the extension strength from the compression strength (both strengths are defined using the ratio between the second and the first invariant of the stress tensor, denoted $I_{1}$ and $s_{I I}$ respectively).

Contrary to before-mentioned criteria, the deviatoric plastic limit criterion of CJS model $[27,29]$ presents two parameters in case the extension and compression strengths are calibrated separately (see Figure 2). The equation of the criterion in the deviatoric plane is written:

$$
s_{I I} h\left(\theta_{s}\right)-R_{\text {lim }} I_{1}=0
$$

with

$$
h\left(\theta_{s}\right)=\left(1-\gamma \cos \left(3 \theta_{s}\right)\right)^{1 / 6}
$$

Angle $\theta_{s}$ is the Lode angle (for example $\theta_{s}=0^{\circ}$ for axisymmetric compression, and $\theta_{s}=60^{\circ}$ for axisymmetric extension), and $I_{1}=\operatorname{tr}(\boldsymbol{\sigma})=3 p$ is the first invariant of the stress tensor. The model parameter $\gamma$ rules the dissymetry of the criterion evidenced by the ratio between compression and extension strengths which is different from unity. For $\gamma=0$ the criterion is circular in the deviatoric plane, which is not adapted to a three-dimensional description of soil behaviour. Finally, $R_{\text {lim }}$ corresponds to the mean radius of the limit surface in the deviatoric plane; this parameter is discussed more in detail in section 2.2.

The limit surface of CJS model, plotted in Figure 3, is compared to Lade criterion for a set of parameters leading to the same values for the extension and compression strengths for both models. One can note that the departure between the two criteria is very small for any other intermediate principal stresses (Figure 3(b)). The plot for Lade criterion in Figure 3 was obtained using the polar expression of this criterion derived in [37].

\subsubsection{Yield criterion}

The elastic domain is strictly included inside the plastic limit surface, with a similar shape as already stated but is written according to a "local" deviatoric stress, $\boldsymbol{q}$. Indeed, a kinematic hardening can move the center of the yield 


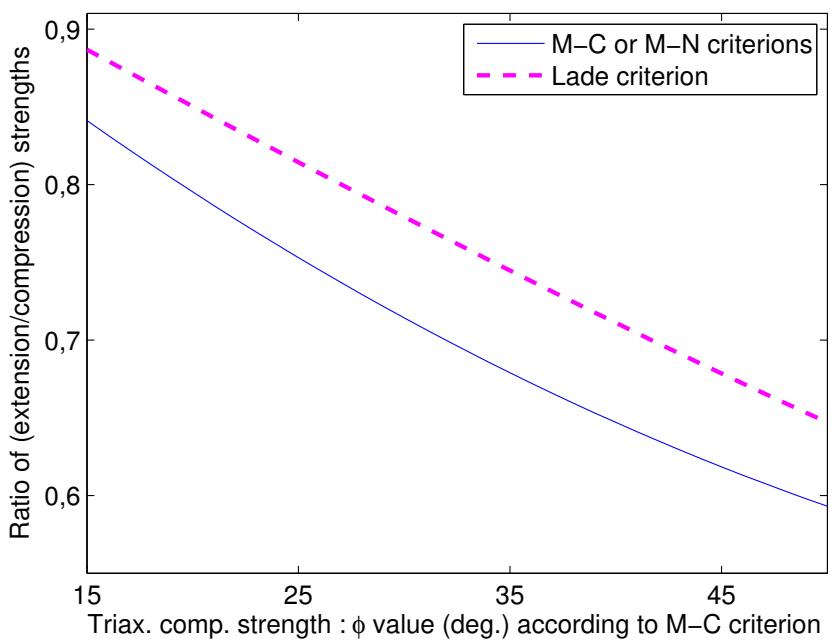

Figure 2: Predictions, Mohr-Coulomb (M-C), Matsuoka-Nakai (M-N), or Lade, criteria of the triaxial extension strength, for a given compression strength. The common value of the compression strength is expressed through Mohr-Coulomb parameter: the internal friction angle $\phi$. No such constraint between extension and compression strengths exists for CJS model.

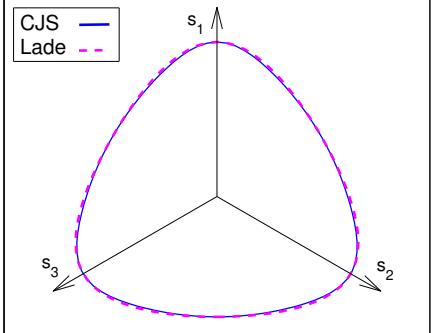

(a) In the deviatoric plane

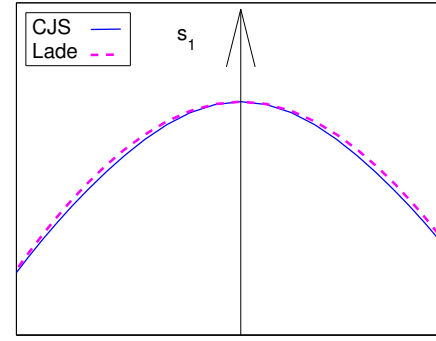

(b) Zoom around the axisymmetric compression state

Figure 3: Comparison between Lade [1,37] and CJS criterion in the deviatoric plane, in the case of common extension and compression strengths. 
criterion away from the hydrostatic axis. We can write: $\boldsymbol{q}=\boldsymbol{s}-I_{1} \boldsymbol{X}$, with $\boldsymbol{X}$ a non-dimensional tensor positioning the center of the yield surface within the principal stress space. Figure 4 depicts the yield criterion in the octohedral plane. The corresponding equation is written:

$$
f=q_{I I}\left(1-\gamma \cos \left(3 \theta_{q}\right)\right)^{1 / 6}-R I_{1}=0
$$

Angle $\theta_{q}$ has to be understood as a local Lode angle (see Figure 4), belonging

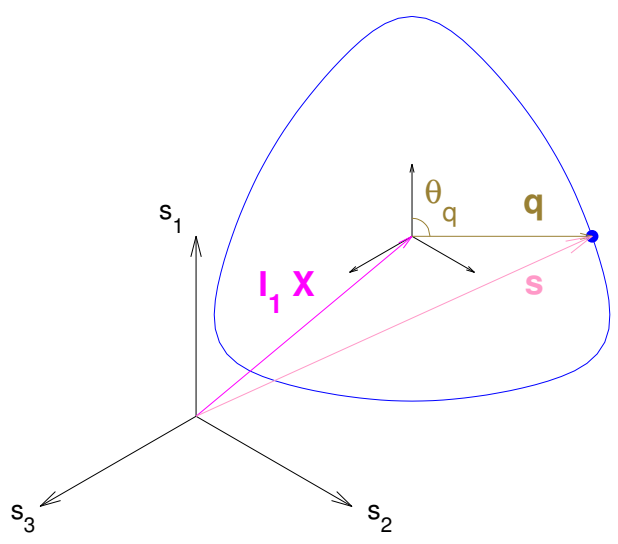

Figure 4: Cross-section in the octohedral plane of the yield surface. The surface, centered at $\mathbf{X}$, restricts the local deviator $\mathbf{q}$.

to the whole interval $\left[0^{\circ} ; 360^{\circ}\right]$.

Apart from changes of $\boldsymbol{X}$, shearing also affects the value of the mean radius $R$ of the surface through an isotropic hardening. Both internal variables $R$ and $\boldsymbol{X}$ tend to a finite value in such a way that the yield surface strictly remains inside the plastic limit domain. For this purpose, a non-linear link between $R$ and its hardening variable $v$ is used:

$$
d R=\frac{A R_{m}^{2}}{\left(A v+R_{m}\right)^{2}} d v
$$

Equation (5) introduces two model parameters: $A$ and $R_{m} . R_{m}$ is the final value of $R$ when $v$ tends to infinity. The evolution of hardening variable $v$ is obtained according to equation (6) which is partly deduced from the generalized standard material (GSM) approach from Halphen and Son Nguyen [38]. The GSM approach was introduced to satisfy the second thermodynamical principle that rules irreversible phenomena.

$$
d v=-d \lambda^{d} \frac{\partial f}{\partial R}\left(\frac{p_{0}}{p}\right)^{1.5}
$$


In equation (6), $d \lambda^{d}$ is the plastic multiplier corresponding to the deviatoric yield criterion, and the extra term $\left(p_{0} / p\right)^{1.5}$, with $p_{0}=100 \mathrm{kPa}$, was introduced after experimental comparisons to damp out the strong influence of the mean pressure in the hardening process [28]. Concerning the evolution of $\boldsymbol{X}$, a linear relation with its kinematic hardening variable $\boldsymbol{\alpha}$ is used but $\boldsymbol{d} \boldsymbol{\alpha}$ is computed in such a way that finite limits for both $\boldsymbol{\alpha}$ and $\boldsymbol{X}$ exist:

$$
\boldsymbol{d} \boldsymbol{X}=a \boldsymbol{d} \boldsymbol{\alpha} \text { and } \boldsymbol{d} \boldsymbol{\alpha}=-d \lambda^{d}\left(\operatorname{dev}\left(\frac{\partial f}{\partial \mathbf{X}}\right)+I_{1} \phi \boldsymbol{X}\right)\left(\frac{p_{0}}{p^{\prime}}\right)^{1.5}
$$

In equation (7), $a$ is a hardening model parameter, and we denote $\operatorname{dev}(\mathbf{T})$ the deviatoric part of any tensor T. $\phi$ is not a model parameter but defined so that $\boldsymbol{d} \boldsymbol{\alpha}$ tends to zero when the yield criterion reaches the plastic limit condition. For example, in axisymmetric conditions, $\phi=1 /\left(R_{\text {lim }}-R_{m}\right)$.

\subsubsection{Plastic potential}

Because plastic volumetric strains for soils can be either contractive or dilative and depend on the magnitude of the deviator stress, the additional strains $\boldsymbol{d} \boldsymbol{\varepsilon}^{\boldsymbol{d} \boldsymbol{p}}$ are computed through the following dilatancy rule:

$$
d \varepsilon_{v}^{d p}=\beta\left(\frac{s_{I I}}{s_{I I}^{c}}-1\right) \frac{\left|s: d e^{d p}\right|}{s_{I I}}
$$

A characteristic state [30] (or Phase Transformation State [39]) separating the contractancy and the dilatancy domains is introduced through $s_{I I}^{c}$. $s_{I I}^{c}$ is the corresponding value of the second invariant of the stress tensor on the characteristic surface associated to the actual mean pressure. For convenience, the characteristic surface has the same shape as the plastic limit or the yield surface and is characterized by a mean radius $R_{\text {char }}$ :

$$
s_{I I}^{c}\left(1-\gamma \cos \left(3 \theta_{s}\right)\right)^{1 / 6}-R_{\text {char }} I_{1}=0
$$

The value for radius $R_{\text {char }}$ is discussed in section 2.2. Negative values for model parameter $\beta$ have to be used so that both dilative $\left(d \varepsilon_{V}^{d p}<0\right.$ for $\left.d \varepsilon_{1}^{d p}>0\right)$ or contractive $\left(d \varepsilon_{V}^{d p}>0\right.$ for $\left.d \varepsilon_{1}^{d p}>0\right)$ behaviours are obtained for $s_{I I}>s_{I I}^{c}$ or $s_{I I}<s_{I I}^{c}$. Irrespective of the contractive or the dilative nature of the behaviour, when $|\beta|$ decreases (under same stress states), the intensity of the plastic deviatoric volumetric strains (slope $\left|d \varepsilon_{V}^{d p} / d \varepsilon_{1}^{d p}\right|$ ) decreases.

The flow rule is not associated, then the plastic potential is different from the yield surface. The details for the computation of the plastic strain tensor, which actually does not require to know the expression of the plastic potential but just the normal to this surface, can be found in [27, 28].

\subsection{Isotropic plastic mechanism}

A second plastic mechanism which allows closing the stress space along the hydrostatic axis is introduced. The corresponding yield surface is a plane 
and the criterion is defined by $p=p_{\text {cons }}$, where $p_{\text {cons }}$ corresponds to the preconsolidation pressure. The activation of this plane generates a plastic strain $\boldsymbol{d} \varepsilon^{i p}$ computed according to an associated flow rule (see Figure 5).

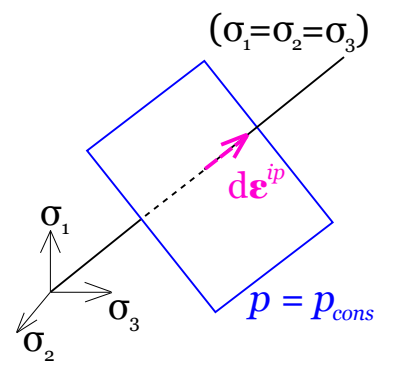

Figure 5: Isotropic plastic mechanism: corresponding yield criterion and flow rule.

The hardening or this plastic surface is ruled by a "plastic compressibility modulus" $K^{p}$ :

$$
d p_{\text {cons }}=K^{p} \operatorname{tr}\left(\boldsymbol{d} \varepsilon^{i p}\right)
$$

Parameter $\Gamma_{e / p}$ relates $K^{p}$ to modulus $K^{e}: K^{p}=K^{e} / \Gamma_{e / p}$. From equation (10), one can note that the evolution of $p_{\text {cons }}$ obeys the formulation of standard generalized materials.

To conclude, the constitutive model CJS gives a relationship between the increment of stress and the increment of total strain as $\boldsymbol{d} \sigma=\mathcal{F}\left(\boldsymbol{d} \varepsilon^{e}+\boldsymbol{d} \varepsilon^{d p}+\right.$ $\left.\boldsymbol{d} \varepsilon^{i p}\right)$ with $\boldsymbol{d} \varepsilon^{e}$ corresponding to the hypoelastic mechanism and $\boldsymbol{d} \varepsilon^{\boldsymbol{d} p}$ and $\boldsymbol{d} \varepsilon^{i p}$ to the deviatoric and isotropic plastic mechanism respectively.

\section{Adaptation of CJS relations to the changes in the internal state of the soil}

CJS relations are adapted to take into account different initial densities and changes within the structure of the soil due to repeated loadings.

\subsection{Properties inside the yield criteria}

Experimental tests suggest that both moduli $K^{e}$ and $G^{e}$ depend on the mean pressure $p$ [40]. This dependency being non linear, a power dependency involving a parameter $n\left(e . g K^{e} \propto(p)^{n}\right)$ is introduced. For an isotropic granular material, the values of moduli $K^{e}$ and $G^{e}$ are also affected by large variations of density. Thus, a dependency with respect to the void ratio $e$ is also adopted. The formulation proposed by Hardin \& Richart [41] is used. Then, to warrant that a constant Poisson is obtained in any case $K^{e}$ and $G^{e}$ are written:

$$
G^{e}=G^{e 0} \frac{(2.17-e)^{2}}{1+e}\left(\frac{p}{p_{0}}\right)^{n} \quad K^{e}=K^{e 0} \frac{(2.17-e)^{2}}{1+e}\left(\frac{p}{p_{0}}\right)^{n}
$$


Three model parameters are involved: $n, G^{e 0}, K^{e 0}$. $G^{e 0}$ and $K^{e 0}$ are reference values for the moduli under a reference pressure $p_{0}$ equal to $100 \mathrm{kPa}$. The value of this reference pressure is not an additional parameter and is arbitrarily chosen equal to the atmospheric pressure.

In fact, the dependency with respect to the void ratio introduces a coupling between elastic and plastic behaviours since the plastic mechanisms of deformation affect also the void ratio. Due to this coupling, the terms of "elastic" or "plastic" strains have to be dealt with carefully. They are no more directly equivalent to "reversible" or "irreversible", as pointed out by Hueckel and Maier [42], and Houlsby and Collins [43, 44]. Indeed, the strain induced by the plastic mechanisms cannot be considered as the difference between the total strains for two states at the same stress anymore. Figure 6 illustrates this. In this Figure, "elastic" strain is defined as the strain associated to an increase of stress through a compliance tensor, which is a possible choice among others.

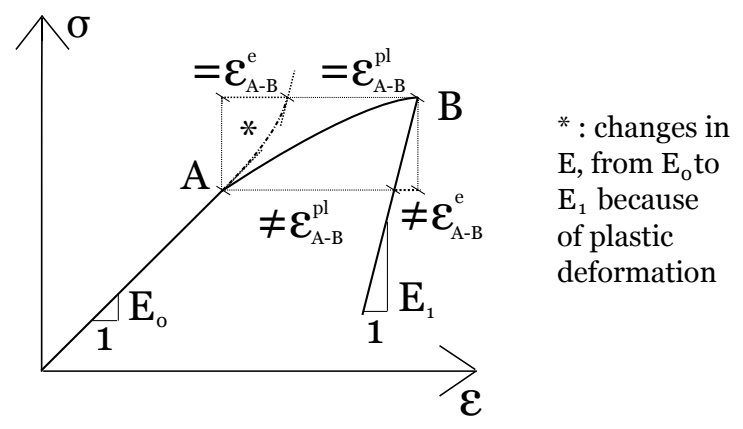

Figure 6: One-dimensionnal example of a material with elastic-plastic coupling: parameter E evolves (only) according to plastic deformation. There is no more equivalence between "elastic/plastic" and "reversible/irreversible" terms. (Inspired by Figure 2 in [43])

Secondly, the pressure-dependency of $G^{e}$ leads to some thermodynamical inconsistencies. Indeed, as shown in [45], equations (1) and (11) do not correspond anymore to a behaviour ruled by a potential energy, function of the strains. Thermodynamical consistent formulations have been proposed by several authors: the discussion by Niemunis \& Cudny[46] summarizes many of the oldest ones. More recently, such formulations can also be found in [47, 48]. In these cases, the constitutive relations are necessarily coupled: the spherical part of the stress tensor depend both on the spherical and deviatoric parts of the strain tensor, contrary to equation (1) which is herein adopted.

In fact, the stress domain inside which equation (1) holds true is not considered in this work as an elastic domain where no irreversibilities take place. Strictly speaking, the elastic behaviour for soils is restrained to strains in a very small domain, for example below $10^{-5}$ for clays under triaxial paths [49, 50], which is much smaller than the domain of strains we are interested in in this work. 
For these reasons, there is no real shortcoming to use the hypoelastic (as defined by Loret [51]) equations (1) and (11). The corresponding constitutive relations are to be understood as describing a behaviour that may reveal some irreversibilities, nevertheless reduced compared to what occurs outside this hypoelastic domain.

Let us finally emphasize that granular soils can probably not be adequately simulated by a sound elasto-plastic theory. In this kind of medium, elastic deformations come from reversible deformations of grains and grain contacts. Then, elastic deformations are ruled by the features of the set of contacts between grains. On the other hand, plastic deformation involve mainly changes in this set of contacts. Then, reversible and irreversible deformations are coupled: an evolving plastic deformation induces changes in the elastic deformation. In elasto-plasticity theory, for a given stress increment, the changes in elastic and plastic deformations are uncoupled.

\subsection{Influences of void ratio and mean pressure}

As stated in the introduction, the whole mechanical behaviour of granular soils, and not only the hypoelastic domain is influenced by the density of the material. Nevertheless, after large deformations, a unique critical state is supposed to be reached [52], where both stresses and volumetric strains do not evolve anymore. In fact, the existence of a unique stable state holds also true for the fabric within the material [53]. For triaxial compression tests, this critical state is completely defined by the value of the mean pressure $p$ (or $I_{1}$ ): whatever the initial state of the soil, the final values for the deviatoric stress $s_{I I}$ and the void ratio $e$ only depend on $I_{1}$. Especially, a unique material parameter $R_{\text {crit }}$ exists, such that, at critical state, $s_{I I} h\left(\theta_{s}\right)=R_{\text {crit }} I_{1}$. Here again, the shape of the critical state surface is derived from the shape of the limit surface.

It has long been recognized that the curve $e_{\text {crit }}(p)$ discriminates the soils between pure contractive and dilative soils [52]: both void ratio $e$ and mean pressure $p$ are to be considered to qualify the behaviour of soils. Soils with an initial state $(e, p)$ such that $e<e_{\text {crit }}(p)$ can contract and dilate, if $e>e_{\text {crit }}(p)$ they can only contract. Been and Jefferies [54] proposed a state variable $\psi$ that should rule the mechanical behaviour of the soil:

$$
\psi=\psi(e, p)=e-e_{\text {crit }}(p)
$$

According to Equation 12, dilative soils (which can contract and dilate) present negative values of $\psi$, whereas positive values correspond to purely contractive soils. The constitutive models for soils proposed by $[19,20,26]$ use the variable

$\psi$ to describe the influences of both the void ratio and the mean pressure on the behaviour of soils. The critical state line $(\mathrm{CSL}) e_{\text {crit }}(p)$ is here supposed to obey the power-law equation (12)

$$
e_{c r i t}(p)=e_{c r i t}^{0}-\lambda_{\text {crit }}\left(\frac{p}{p_{0}}\right)^{\xi}
$$


with $e_{\text {crit }}^{0}, \lambda_{\text {crit }}$ and $\xi$ model parameters defining the critical state line. As large changes in the internal state of the soil (variable $\psi$ ) may occur throughout loadings, the mechanical properties of the sand can significantly evolve. Then, the mean radii of the different surfaces corresponding to different reference states (characteristic state, plastic limit state) of CJS constitutive model are set dependent on $\psi$. For an initially dense sand which dilates due to shearing and hence gets looser, $R_{\text {lim }}$ decreases towards $R_{\text {crit }}$, and $R_{\text {char }}$ increases until $R_{\text {crit }}$, so that the properties of the critical state are retrieved. That also means that the softening observed for a dense sand after the peak of shear resistance is modeled since the plastic limit condition here collapses towards the critical surface (see Figure 7). Experiments by $[55,16]$ attest the changes in $R_{\text {char }}$ according to the void ratio and the confining stress and those by $[56,57]$ attest the dependency of the internal friction angle (and thus of $R_{l i m}$ ) with the void ratio and the confining stress. Bi-linear evolutions for the mean radii $R_{c h a r}$ and $R_{l i m}$ are

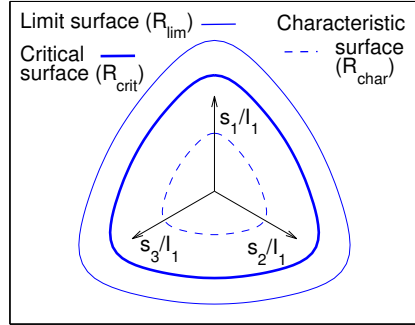

(a) Dilative sand $(\psi<0)$

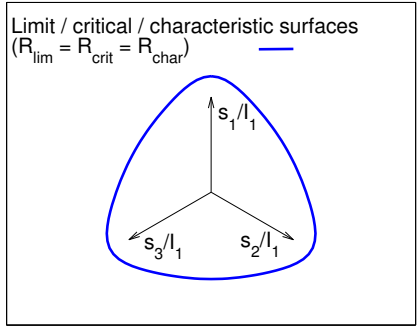

(b) Purely contractive sand $(\psi>0)$

Figure 7: The different constitutive surfaces, in different cases (a common value for $R_{\text {crit }}$ exists between the two cases).

proposed, introducing two positive model parameters $\alpha_{\text {lim }}$ and $\alpha_{\text {char }}$ (see also Figure 8):

$$
\begin{array}{r}
R_{\text {char }}=\min \left(R_{\text {crit }}\left(1+\alpha_{\text {char }} \psi\right), R_{\text {crit }}\right) \\
R_{\text {lim }}=\max \left(R_{\text {crit }}\left(1-\alpha_{\text {lim }} \psi\right), R_{\text {crit }}\right)
\end{array}
$$

Within a different framework, similar dependencies were introduced by [26] for

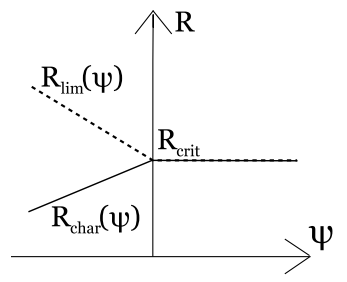

Figure 8: Changes in the characteristic and limit surfaces of the CJS model, according to $\psi$. 
the size of the bounding strength surface, and of the dilatancy rule. Moreover, some numerical simulations involving the Discrete Element Method showed that both radii $R_{l i m}$ and $R_{\text {char }}$ also depend on induced anisotropy [58, 59]. But for the sake of simplicity, the dependency with respect to the density of the soil is only considered in this work.

Dilative materials show specific features like the existence of a peak of shear resistance and softening with a stiffer behaviour before the peak than observed for purely contractive material [16]. Then, the properties of the plastic behaviour must also take into account a dependency with respect to $\psi$. For example, the parameter $a$ (Equation 7) involved in the kinematic hardening is written as:

$$
a=a_{0} \exp \left(-\alpha_{a} \psi\right)
$$

with $a_{0}$ and $\alpha_{a}$ two positive model parameters.

Finally, the intensity of dilation increases when the value of $\psi$ decreases $(|\psi|$ increases). This intensity is directly related to the value of the model parameter $\beta$ (see section 1.2.3) which absolute value must increase with $|\psi|$. Then, $\beta$ is written:

$$
\beta=\beta_{0} \exp \left(\alpha_{\beta} \psi\right)
$$

with $\beta_{0}$ and $\alpha_{\beta}$ two negative parameters.

\subsection{Induced anisotropy}

Different experiments or numerical studies involving the Discrete Element Method have evidenced that the set $(e, p)$ is not the only variable that influences the mechanical response of a sand. Indeed, the behaviour of granular materials also depends on the direction of the loading with respect to the contact directions of grains. Physical experiments on rolled cylinders performed by [60] revealed that the stiffness of the sample can be divided by ten depending on the contact directions in the sample. The volumetric behaviour is also affected, especially the amount of contractive volumetric deformations. Numerical experiments (e.g. [61]) showed also different responses depending on the contact direction of grains within the samples. Irrespective of the initial anisotropy (that can be caused by the construction of the sample under gravity), the orientation of normals at contact conforms the direction of the major principal stress when shearing $[62,63,60]$. Recently, micro-computed tomography on sand confirmed it again [64]. For this reason, Wan \& Guo [25] proposed a model which properties rely on a "fabric tensor" computed proportionally to the deviatoric stress tensor.

In CJS model, induced anisotropy is described through the non-dimensional tensor $\boldsymbol{X}$ related to the kinematic hardening. Indeed, for equal principal stresses $\left(\sigma_{1}, \sigma_{2}=\sigma_{3}\right)$ and loading, e.g. $\left(d \sigma_{1}>0, d \sigma_{2}=d \sigma_{3}=0\right)$, the mechanical response can be either hypo-elastic, or elasto-plastic (Figure 9). In Figure 9, consider the center $\boldsymbol{X} I_{1}$ of the yield criterion at location $\boldsymbol{X}^{\mathbf{1}} I_{1}$ and let us consider an increment of stress so that $\left(d \sigma_{1}=d \sigma_{z z}>0, d \sigma_{2}=d \sigma_{x x}=0, d \sigma_{3}=d \sigma_{y y}=0\right)$. 


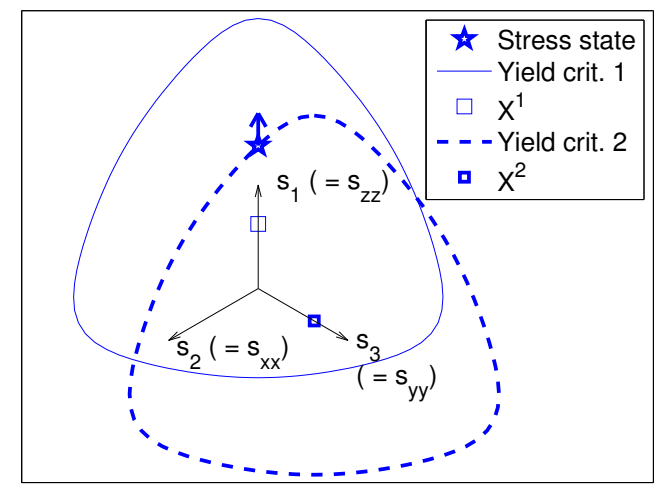

Figure 9: Induced anisotropy: from a given stress state, the response is different depending on $\boldsymbol{X}$, i.e. the previous history. Here the major principal direction corresponds to the physical direction $z$, and the two minor principal directions to $x$ and $y$.

The actual stress state being inside the hypo-elastic surface, the material response is hypo-elastic, with a high stiffness and contractive volumetric deformations. In a second case, for another location of $\boldsymbol{X} I_{1}\left(\boldsymbol{X} I_{1}=\boldsymbol{X}^{2} I_{1}\right)$, the actual stress state is on the yield criterion with an increment of stress directed outward. The response to the same increment $\boldsymbol{d} \boldsymbol{\sigma}$ is elasto-plastic, with lower stiffness and volumetric deformations that can be dilative.

Then, the prediction of the behaviour through CJS model depends not only on the value of principal stresses, but also in the most elementary way, on the principal directions of $\boldsymbol{\sigma}$ (compared to the principal directions of $\boldsymbol{X}$ ). This approach that uses the kinematic hardening is also used for example in MIT-S1 model [24] and was briefly explained in [28]. Tensor $\boldsymbol{X}$ is supposed to model the influence of the induced anisotropy on the behaviour of the material. In fact, discrete simulations by [65] showed that strong correlation exists between $\boldsymbol{X}$ and the fabric (anisotropy of normals' directions at contact grains).

Finally, CJS model requires 17 independent parameters. An example of calibration and validation of CJS model is provided for Fontainebleau sand in section 4.1.

\section{Interface constitutive model for soil-structure}

In geotechnical problems involving any structure in contact with a soil, the zone of soil in contact with the structure exhibits specific features different from both the structure and the soil. In this zone, the soil particles are indeed neither glued to the structure, nor prone to free relative displacements (without any resisting forces). Thus, the behaviour of this zone must be modelled using specific 
constitutive equations. They relate the increments of normal and tangential stresses acting along the interface to the increments of normal and tangential relative displacements. Only one tangential direction is generally considered, like in $[66,67,68,69,70]$.

Experiments showed that the behaviour of this interface is qualitatively ruled by the ratio between the roughness of the structure and the representative particle size of the soil [71]. Different experiments on sand - steel interfaces [66, 72, 71] revealed that the behaviour of smooth interfaces is elastic-plastic, with no relative normal displacements [71] or reduced ones [66, 72] whereas a more complex behaviour was obtained for rough interfaces. The complex behaviour for such interfaces is confirmed by other works $[73,67,74]$. We can draw a parallel between the behaviour of a rough interface and the behaviour of a granular soil provided that a normal stress dependency of the behaviour replaces the mean pressure dependency [73, 67]. Indeed, like for soils, some experiments have shown both the influence of the normal stress and of the void ratio inside the interface on the behaviour of the rough interfaces $[66,74]$.

For rough interfaces, a constitutive model accounting for the internal state of the interface is then clearly advantageous. While modellings proposed by [66, 68] require different parameters for loose or dense samples, works by $[67,69]$ take into account both the influence of density and of the constant normal stress. However, these authors have only validated their models using monotonic loadings. Liu \& Ling [70], extending their previous work [69], presented validations of their model regarding cyclic tests. Their formulation, within the generalized plasticity framework, included the $\psi$ state parameter that is used for soil modelling in section 2.2. However, Liu \& Ling considered that the cyclic response of the interface is ruled by particle breakage. Hence, in their model, the CSL of the interface shifts along $e$-axis during the cyclic loading, according to the evolution of the plastic work. Then, a densification is obtained in the interface due to the filling of voids by new fine particles created after the breakage of larger particles. The peak stress ratio is also considered to evolve according first to $\psi$ but also to the plastic work.

In this work, the dependency of the behaviour with respect to the void ratio in the interface and the normal stress will only be kept. The design of a constitutive model for a rough interface from a constitutive model for soil is performed replacing on the one hand the mean pressure $p$ by the normal stress $\sigma$ and the deviatoric stress tensor $s$ by the (scalar) tangential stress $\tau$. On the other hand, the normal relative displacement $u$ is considered as equivalent to the volumetric strain $\varepsilon_{V}$, whereas the tangential relative displacement $\gamma$ replaces the deviatoric strain. Positive signs for $\sigma$ and $u$ still correspond to compression. A critical state line is also identified. For the sake of simplicity, it is chosen as linear in $(e, \ln (\sigma))$ plane:

$$
e_{c r i t}^{i}=e_{c r i t}^{0 i}-c_{c r i t} \ln \left(\frac{\sigma}{\sigma_{0}}\right)
$$




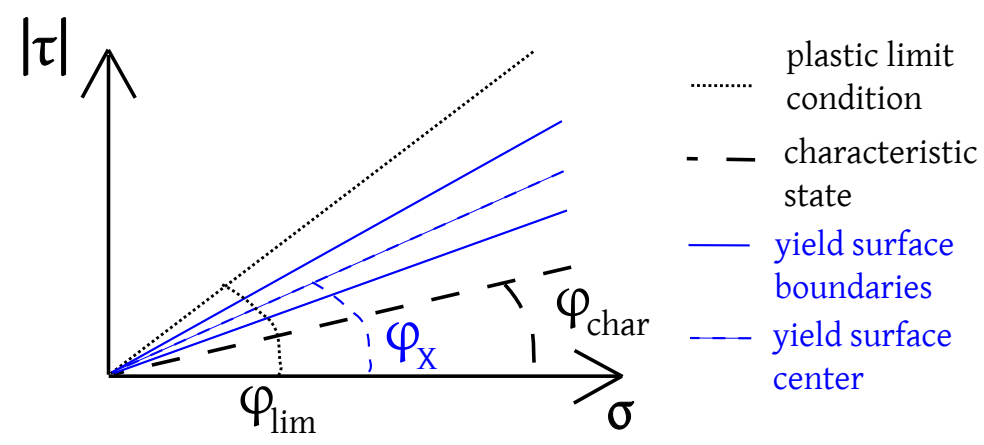

Figure 10: CJSi constitutive model for rough interfaces: different domains in the Mohr plane for a dense interface.

The interface void ratio evolves according to the interface normal relative displacements, from an initial value that is supposed to be the one of the surrounding soil. Moreover, a given thickness for the interface must be assumed. Different authors measured this interface thickness analyzing the displacement field along an interface experiencing shearing, e.g. [71, 75]. In these studies, the deformations caused by the structure displacements seemed to concentrate in a layer as thick as 5-10 times the mean diameter of the sand involved in the interface. Here, like in [67], the interface thickness $t$ is supposed to be equal to ten times the mean diameter of the sand in the interface $\left(D_{50} \approx 0.22 \mathrm{~mm}\right.$ for Fontainebleau sand studied in section $4^{2}$ ). Then, the variation of the interface void ratio can be determined from the incremental relative normal displacements through equation (17):

$$
d e=-\frac{d u}{t}(1+e)
$$

Figure 10 summarizes the main features of the constitutive model CJSi, for rough interfaces, derived from CJS model. Being cohesionless, the material in the interface cannot bear traction and the ratio $|\tau| / \sigma$ is limited by the maximum value $|\tau| / \sigma=\tan \left(\varphi_{\text {lim }}\right)$. The density of the interface affects both angles $\varphi_{\text {lim }}$, and $\varphi_{\text {char }}$ that rule the plastic behaviour (see also section 3.2). The stress ratio at critical state is deduced from the parameter $\varphi_{\text {crit }}$ :

$$
|\tau| / \sigma=\tan \left(\varphi_{\text {crit }}\right)
$$

Angles $\varphi_{\text {char }}$ and $\varphi_{\text {lim }}$ which are distinct for dilative interfaces are equal to $\varphi_{\text {crit }}$

\footnotetext{
${ }^{2}$ Note that for Fontainebleau sand, $D_{50}$ 's value may be fairly considered as constant even considering particle crushing (that is not the case here). Various interface experiments show indeed that particle crushing in Fontainebleau sand affects the smallest particles, that is: $D_{10}$; while $D_{50}$ variations remain more limited $(<15 \%)$ than for other sands [76, 77].
} 
for purely contractive interfaces:

$$
\begin{aligned}
& \tan \left(\varphi_{\text {char }}\right)= \begin{cases}\tan \left(\varphi_{\text {crit }}\right)\left(1+\alpha_{\text {char }}^{i} \psi\right) & \text { if } \psi<0 \\
\tan \left(\varphi_{\text {crit }}\right) & \text { if } \psi>0\end{cases} \\
& \tan \left(\varphi_{\text {lim }}\right)= \begin{cases}\tan \left(\varphi_{\text {crit }}\right)\left(1-\alpha_{\text {lim }}^{i} \psi\right) & \text { if } \psi<0 \\
\tan \left(\varphi_{\text {crit }}\right) & \text { if } \psi>0\end{cases}
\end{aligned}
$$

Both parameters $\alpha_{c h a r}^{i}$ and $\alpha_{l i m}^{i}$ in Equation (19) are positive. This way, dilative interfaces exhibit a stress peak and dilatancy when sheared, while purely contractive ones do not exhibit a distinct peak and with only contractive normal relative displacements.

The behaviour can be hypo-elastic depending on the value of the local tangential stress $\tau_{q}$ :

$$
\tau_{q}=\tau-\sigma \tan \left(\varphi_{X}\right)
$$

A kinematic hardening is considered: the hardening parameter $\varphi_{x}$ corresponds to the center of the yield surface (Figure 10). Equation (21) defines the yield surface boundaries (see also Figure 10):

$$
\left|\tau_{q}\right|-\sigma \tan \left(\varphi_{e}\right)=0
$$

An isotropic hardening is also considered through the evolution of $\varphi_{e}$. The equations that rule the evolution of $\varphi_{X}$ and $\varphi_{e}$ involve two parameters, $a^{i}$ and $A^{i}$ respectively. They are similar to those for $\boldsymbol{X}$ and $R$ in CJS model (see [78] for more details).

\subsection{Hypoelastic mechanism}

Inside the yield surface previously defined, a linear relation links $\overrightarrow{d \sigma}=$ $(d \sigma, d \tau)$ to $\overrightarrow{d l}=(d u, d \gamma)$. It is an uncoupled relation, with stiffnesses depending both on the normal stress and on the relative density $I_{D}$ (see also $[69,79]$ ):

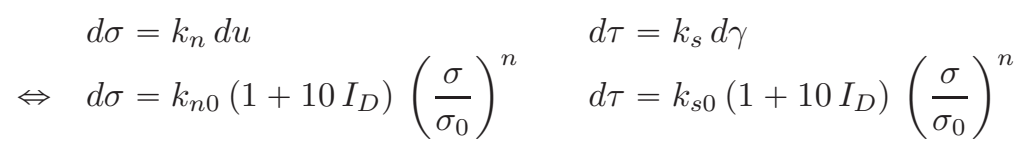

Equation (14) includes two parameters: $k_{n 0}$ and $k_{s 0}$ whose values are related to $\sigma_{0}$ that is a reference stress and thus not an additional parameter.

\subsection{Plastic mechanism}

For a stress state on the yield surface, when the stress increment is directed outward, plastic yield occurs. The plastic normal displacement can be contractive if $|\tau| / \sigma<\tan \left(\varphi_{\text {char }}\right)$ or dilative for $|\tau| / \sigma>\tan \left(\varphi_{\text {char }}\right)$. Equation (19) involving the parameter $\psi$ modifies the value of $\varphi_{\text {char }}$ and allows purely contractive or dilative interfaces to be modeled. The intensity of the normal displacements is ruled by a parameter $\beta^{i}$ through an equation similar to equation (8) previously presented for the element of soil volume. The internal state 
of the interface is considered as affecting not only $\varphi_{\text {char }}$ but also the intensity of normal displacements:

$$
\beta^{i}=\beta_{0}^{i} \exp \left(\alpha_{\beta}^{i} \psi\right)
$$

Equation (23) involves two parameters $\beta_{0}^{i}$ and $\alpha_{\beta}^{i}$. Note that, like for $\beta$ in CJS model, $\beta^{i}$ is negative.

Finally, CJSi model has 13 parameters, including two of them describing the CSL. It is designed to model the behaviour of rough soil-structure interfaces irrespective of the interface density state. If $\psi<0$, for states such that $\tau / \sigma>$ $\tan \left(\varphi_{\text {char }}\right)$, the behaviour is dilative $(d u<0)$ under elasto-plastic loading, and a peak for the mobilized friction $\tau / \sigma$ is exhibited. If $\psi>0$, only contractive deformations occur $(d u>0)$ and no peak for the mobilized friction appears. Smooth interfaces can also be simulated setting null values for parameters $\beta_{0}^{i}$ and $\alpha_{\beta}^{i}$. Comparisons with experimental data for Fontainebleau sand are presented in section 4 .

\section{Case study involving a pile-soil interaction}

A boundary value problem that constitutes the subject of a blind benchmark in the national project SOLCYP is studied. The problem to solve involves an axially cyclic loaded pile placed in a Fontainebleau sand massif. The ruguosity of the pile is about 0.44 times the mean diameter of the Fontainebleau sand, $D_{50}$, the interface may thus be considered as rough [72]. The constitutive model CJS for the element of soil volume and the model CJSi for the pile-soil interface are used. Table 1 lists the physical properties of Fontainebleau sand, and its particle size distribution is depicted in Figure 11.

$$
\begin{array}{|c|c|c|}
C_{U} & e_{\min } & e_{\max } \\
\hline 1.49 & 0.510 & 0.882
\end{array}
$$

Table 1: Physical properties of Fontainebleau sand.

\subsection{Calibration and validation of CJS model for Fontainebleau sand}

Triaxial tests involving samples of Fontainebleau sand [80] and performed in Navier laboratory, partner of the project SOLCYP, are used to calibrate CJS model. They are also used to check its predictive ability. The tests cover a wide range of initial $(e, p)$ values but only monotonous tests were performed.

Three tests, denoted $\mathrm{C} 1, \mathrm{C} 2$ and $\mathrm{C} 3$ in Table 2, are used to calibrate the parameters of CJS model. Some assumptions for parameters $K^{e 0}$ and $\Gamma_{e / p}$ are made and verified with a back-analysis of the experimental volumetric deformation curves. For given values of these parameters, the volumetric deformation due to the hypo-elastic and the isotropic plastic mechanisms can be analytically computed. Then, the third part of the volumetric deformations coming from the deviatoric plastic mechanism can be isolated from the experimental data. 


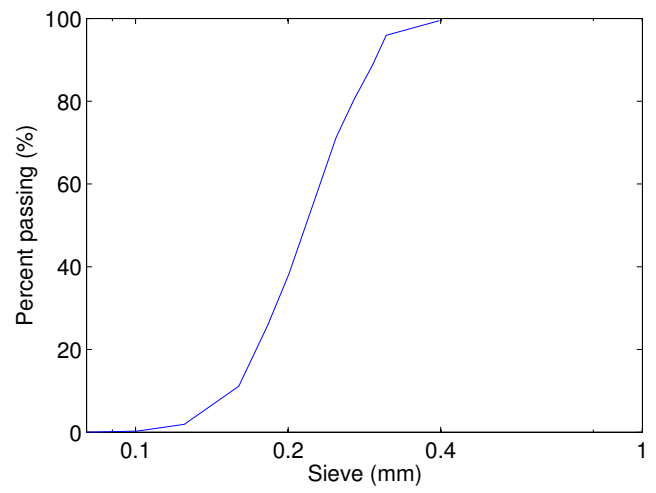

Figure 11: Particle size distribution curve of Fontainebleau sand

\begin{tabular}{|c|c|c|c|} 
Test name & Initial void ratio & $I_{D}(\%)$ & Confining pressure $(\mathrm{kPa})$ \\
\hline C1 & 0.709 & 46 & 400 \\
C2 & 0.638 & 66 & 200 \\
C3 & 0.573 & 83 & 50 \\
V1 & 0.637 & 66 & 50 \\
V2 & 0.637 & 66 & 400 \\
V3 & 0.579 & 81 & 100
\end{tabular}

Table 2: Triaxial tests on Fontainebleau sand used for the calibration and the validation of CJS model.

Assumed values for $K^{e 0}$ and $\Gamma_{e / p}$ are considered as adequate when this latter volumetric deformation exhibits a contractive-dilative transition as expected for poorly dilative sands. Therefore, due to the lack of experiments under an isotropic path, the identification of these latter parameters is only provided qualitatively.

In order to determine the CSL parameters, we use assumptions formulated by Biarez [81]. They state that maximum and minimum void ratios $e_{\max }$ and $e_{\min }$ [82] are states belonging to the Critical State Line for approximately $p=0.1 \mathrm{MPa}$ and $p=5 \mathrm{MPa}$ respectively.

Because only triaxial compressions tests are available, the parameter $\gamma$ is determined assuming that the CJS yield criterion presents the same ratio between triaxial compression and extension strengths as predicted by Lade criterion (Figure 3 ). The radius of the critical surface, $R_{\text {crit }}$ is then obtained thanks to the plateau of test $\mathrm{C} 1$ (see Figure 12). The maximum value for the hypo-elastic radius $R_{m}$ is supposed to be equal to half of $R_{\text {crit }}$ (available cyclic tests would have allowed to investigate this point more in detail). Parameter $\alpha_{\text {lim }}$ is identified in such a way that peaks of resistance in tests $\mathrm{C} 2$ and $\mathrm{C} 3$ can be retrieved. The hardening parameters $a_{0}, \alpha_{a}, A$ are obtained after a trial-and-error method to get back the whole stress curves. Finally, the parameters for the plastic potential 
are also obtained through a trial-and-error method, thanks to the experimental volumetric deformation curves.

The identification of CJS model parameters would have been of better quality on the basis of an isotropic compression test (presenting a loading and an unloading phase), a deviatoric compression test involving an unloading until reaching the peak in the extension domain and a one-way cyclic deviatoric test so that the hypo-elastic domain may reach its widest extent. Despite this lack of information, a very good agreement is obtained between the experimental results and CJS model except for the volumetric deformation curve for test C2 (Figure 12). It means that the calibrated CJS parameters satisfactorily match the experimental data. The values for the parameters of CJS model are summarized in Table 3.
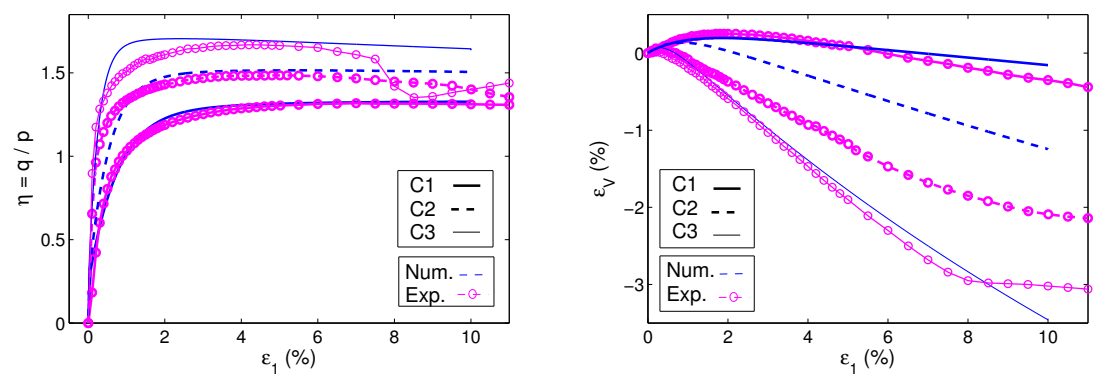

Figure 12: Calibration of CJS model with triaxial tests on Fontainebleau sand.

\begin{tabular}{|c|c|c|c|c|c|c|c|c|c|c|}
\hline & po-elasti & and & isotropic & plas & stic & echanisms & Criti & l state & ine & \\
\hline & $(\mathrm{MPa})$ & $G^{e}$ & $(\mathrm{MPa})$ & $n$ & & $\Gamma_{e / p}$ & $e_{\text {crit }}^{0}$ & $\lambda_{\text {crit }}$ & $\xi$ & \\
\hline & 250 & & 35 & 0.5 & & 2 & 0.899 & 0.017 & 0.8 & \\
\hline & & & Devi & ator & ic p & stic mechar & & & & \\
\hline & & ld ar & plastic & limi & $\mathrm{tcri}$ & erions & & Plas & c poten & \\
\hline$\gamma$ & $R_{\text {crit }}$ & $\alpha_{l i m}$ & & & $\alpha_{a}$ & $A\left(\mathrm{~Pa}^{-1}\right)$ & $R_{m}$ & $\alpha_{\text {char }}$ & $\beta_{0}$ & $\alpha_{\beta}$ \\
\hline 0.686 & 0.255 & 1.8 & 16.310 & & 3 & $1510^{-5}$ & 0.125 & 0 & -0.139 & -5 \\
\hline
\end{tabular}

Table 3: Identified parameters for CJS model for Fontainebleau sand ( $p_{0}=100 \mathrm{kPa}$ ).

Once CJS model has been calibrated from tests $\mathrm{C} 1$ to $\mathrm{C} 3$, three other tests V1 to V3 (Table 2) are used for validation purpose. A good agreement is then obtained for both the deviatoric stress path and the volumetric deformations (Figure 13) which confirms the relevance of CJS model.

\subsection{Calibration of the interface parameters}

Fontainebleau sand was used by [83] as an interface medium along a rough steel structure. Two interface shear tests under constant normal load $(\sigma=100$ 

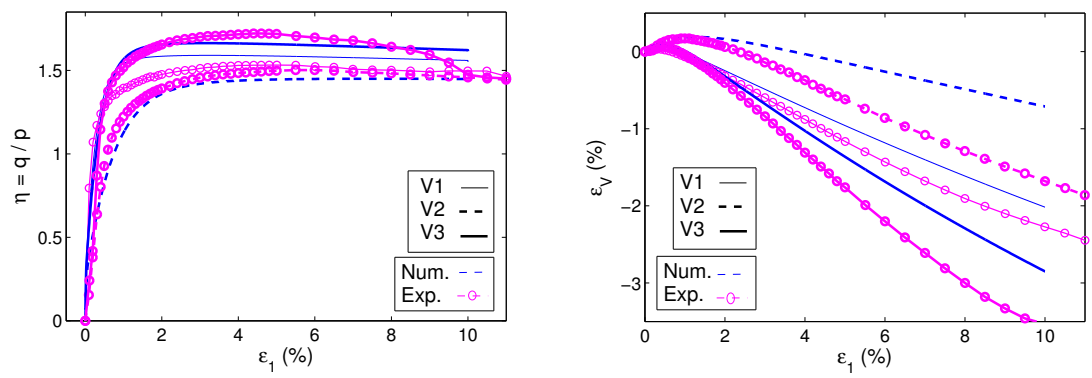

Figure 13: Validation of CJS relation on triaxial tests on Fontainebleau sand.

$\mathrm{kPa}$ ), for two soil densities, were performed. Each test presents two loading reversals. CJSi parameters are calibrated using the experiments according to a procedure similar to the one used for the calibration of CJS model. The result of the calibration process is presented in Figure 14 for the parameters listed in Table 4 . The simulation curves are considered as in a good agreement with the experiments.

\begin{tabular}{|c|c|c|c|c|c|c|c|c|}
\hline & \multicolumn{4}{|c|}{ Hypo-elastic mechanism } & \multicolumn{3}{|c|}{ Critical state line } & \\
\hline & $\begin{array}{c}k_{n 0}(\mathrm{MPa} \\
550\end{array}$ & & $\begin{array}{c}k_{s 0}(\mathrm{MPa} / \mathrm{m}) \\
200\end{array}$ & $\begin{array}{c}n \\
0.5\end{array}$ & $\begin{array}{l}e_{\text {crit }}^{0} i \\
0.71\end{array}$ & & & \\
\hline \multicolumn{9}{|c|}{ Deviatoric plastic mechanism } \\
\hline \multicolumn{6}{|c|}{ Yield and plastic limit criteria } & \multicolumn{3}{|c|}{ Plastic potential } \\
\hline$\overline{\tan \left(\phi_{\text {crit }}\right)}$ & \begin{tabular}{l|l}
$\left.t^{\prime}\right)$ & $\alpha_{\text {lim }}^{i}$
\end{tabular} & $a$ & \begin{tabular}{l|l} 
& $A^{i}\left(\mathrm{~Pa}^{-1}\right)$
\end{tabular} & $\tan ($ & $\overline{\left.\phi_{m}\right)}$ & $\alpha_{\text {char }}^{i}$ & $\beta_{0}^{i}$ & $\alpha_{\beta}^{i}$ \\
\hline 0.8 & 0.6 & 0.0 & 0.02 & 0. & & 2 & -0.308 & -2 \\
\hline
\end{tabular}

Table 4: CJSi parameters (for $\sigma_{0}=100 \mathrm{kPa}$ ) for a rough interface composed of Fontainebleau sand.

At the time of the project, no other data for the same system were available. Thus, CJSi model cannot have been validated at a homogeneous scale. Section 4.3 involving the interface relation in a boundary value problem contributes in a certain extent to validate CJSi model for Fontainebleau sand interfaces. Homogeneous scale calibration and validation were previously proposed for other interfaces [78].

\subsection{Cyclic axial loading simulation of a pile}

A cyclic axial loading of a pile built in Fontainebleau sand is finally considered. Small-scale experiments were performed with a centrifuge device in the French Institute IFSTTAR [84], partner of SOLCYP project. Herein, a numerical simulation of the experiments is proposed, using FLAC software (code ITASCA) in which CJS and CJSi models have been previously implemented. The set of model parameters used in the study is the one previously identified 

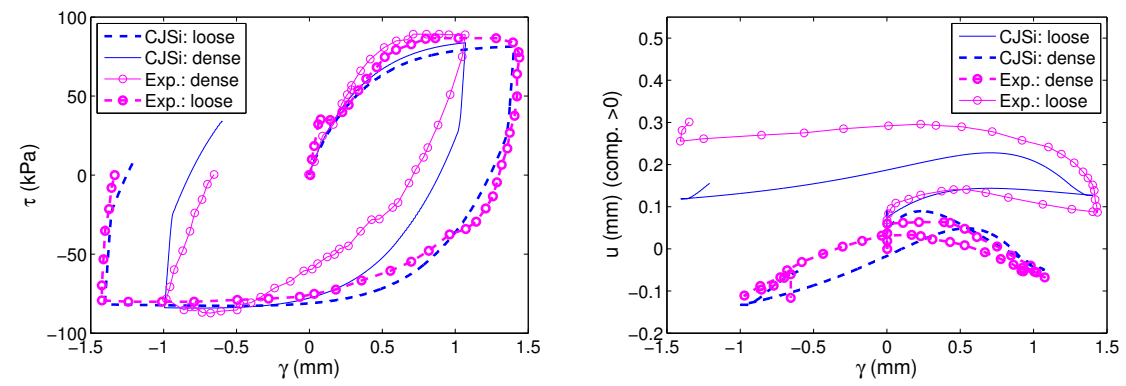

Figure 14: Calibration of the parameters CJSi interface model.

for Fontainebleau sand. The void ratio is initially equal to $0.555\left(I_{D} \approx 88 \%\right)$, in both experiments and simulations.

In the actual experiments, the pile is first maintained in its final position, before filling the tank with the sand. Therefore, the pile is not driven into the granular material. The tank width is equal to ten times the pile radius. Then, the hypothesis of an axisymmetric isolated pile in a semi infinite sand massif holds true. This system is depicted in Figure 15. In the model, displacements in $\vec{x}$ direction are prohibited along $\mathrm{AB}$ and $\mathrm{CD}$ sides, while $\vec{y}$-displacements are prohibited along CB. The soil is discretized into zones (elements) whose behaviour is ruled by CJS model. A sufficient number of elements is chosen (Figure 16) to obtain a response independent of the meshing. The metallic pile is also discretized and behaves elastically with appropriate parameters. Numerical interfaces between pile and soil zones are ruled by the previously calibrated CJSi model. Interfaces simulation involve a high number of nodes, related to the number of zones. The CJSi model is applied for each node, according to the relative displacements occuring at the node. This provides a local description of the behaviour.

The CJS model being designed for granular soils, cases with $p<0$ cannot be handled. In order to avoid divergences of the computations at the top surface of the sand massif because of excessive low values for $p$, an isotropic stress state of $5 \mathrm{kPa}$ is added to each zone of the model, together with an external pressure of the same value along DA.

First, a monotonic compression is simulated by imposing a constant velocity for the nodes at the top of the pile. The speed is chosen low enough so that a quasi-static loading condition holds true. This condition was satisfied since the stress state has not evolved when the loading was kept at a given constant value. The numerical and experimental evolutions of the vertical force acting on the pile are compared in Figure 16.

No clear plateau is obtained with the numerical model, while one was observed in the experiments. Moreover, in spite of a discrepancy found for the initial stiffness (the numerical stiffness overestimates the experimental one by roughly $70 \%$ ), the result can be qualified as in a good agreement with the ex- 


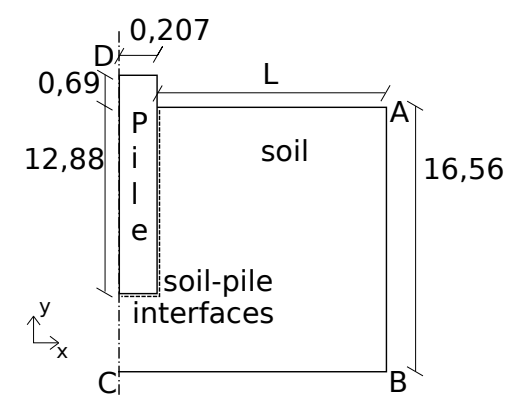

Figure 15: FLAC numerical model.

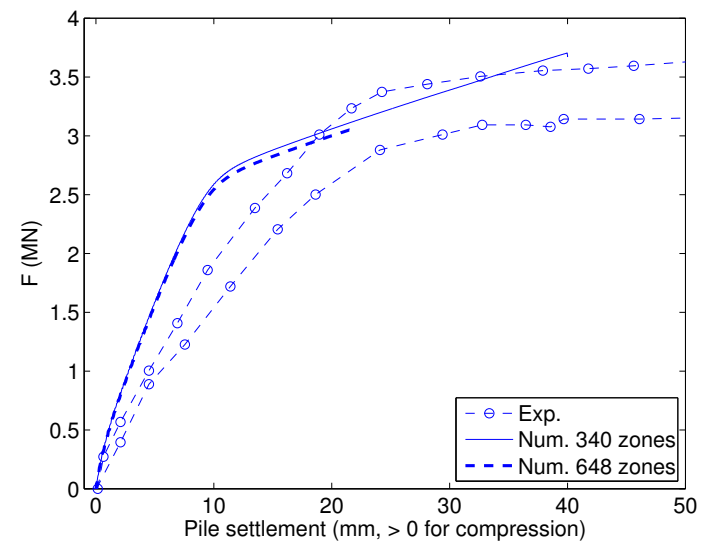

Figure 16: Experimental and numerical monotonic compression tests. The two experimental tests allow the repeatability of experiments to be catched. The two numerical curves allow the independency with respect to the mesh discretization to be checked.

periments.

Axial cyclic loadings that were also performed on the pile are also simulated. A stress control at the top of the pile allows to follow a two-ways cyclic loading path between two extreme values for the vertical force, one on the compressive side $F_{c}^{\max }$ and the other one on the tensile side for the pile: $F_{t}^{\max }$, see Figure 17. $F_{c}^{\max }$ is approximatively equal to $2 \mathrm{MN}$ which is not too severe compared to the maximum pile strength (see Figure 16 ). Moreover, $F_{c}^{\max } \approx 7\left|F_{t}^{\max }\right|$, thus the cycle is mainly compressive. Six cycles of loading were simulated. During the cycles, the pile settlement increases due to the shaft load reduction. In Figure 17, a shaft load reduction of about $18 \%$ is indeed observed during the first six cycles. While the maximum mobilized friction angle remains constant in the lateral interface (Figure 18a), the tangential shear stress decreases due to the decrease of the normal stress (Figure 18b). The normal stress reduction is caused by contraction of the soil around the pile within a zone that extends 
approximatively up to 5 times the radius of the pile.

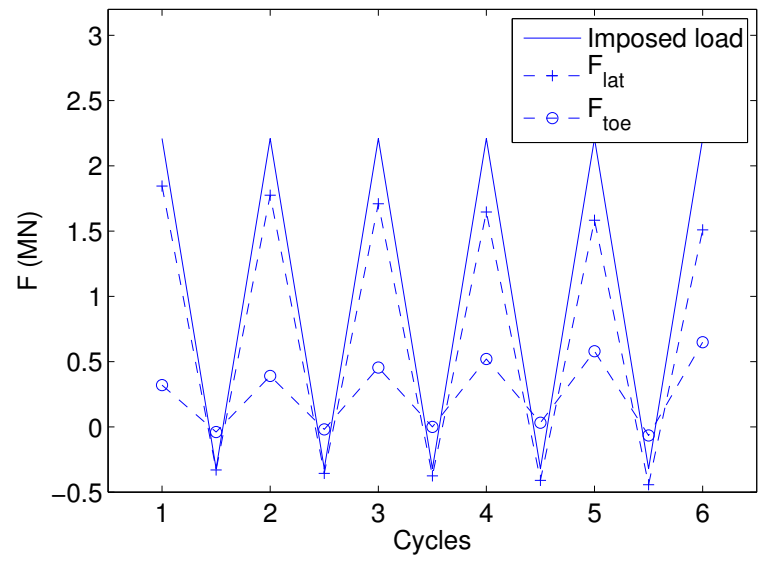

Figure 17: Extreme values of toe and shaft loads during cycles.

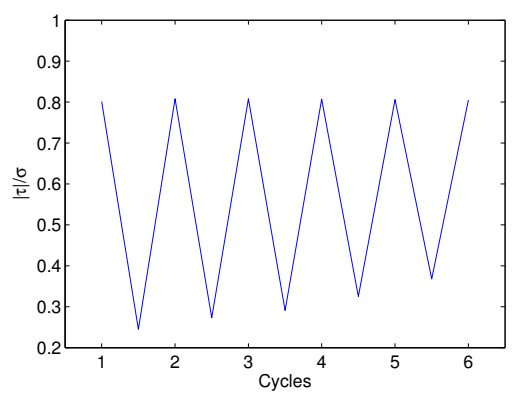

(a) Mobilized friction angle

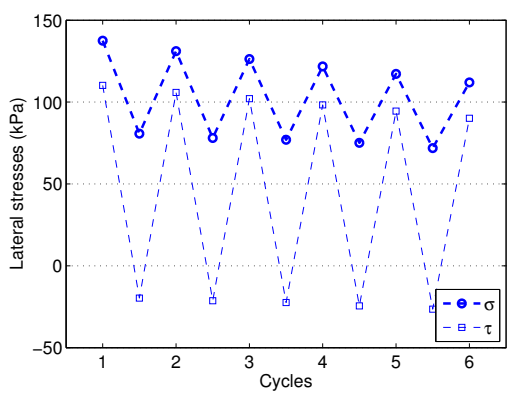

(b) Tangential and normal stresses

Figure 18: Extreme stress states of the lateral interface during cycles.

If we extrapolate the vertical settlement changes through a linear trend, the number of cycles of $F_{c}^{\max }$ leading to a settlement equal to $10 \%$ of the pile diameter can be estimated. The result is given in Table 5 together with the simulated settlement after the first loading and compared to the experimental results. For such compressive loading cycles, the agreement is found satisfactory. In particular, the numerical model of the experimental test approximates the number of cycles triggering "failure" in a good manner. The experimental result is underestimated by around $36 \%$, which is on the conservative side.

\section{Conclusion}

In this work, a constitutive model for granular soils and a constitutive model for rough soil-structure interfaces involving a granular soil have been presented. 


\begin{tabular}{|c|c|c|} 
& Num. & Exp. \\
\hline Vertical displacement after first loading (mm) & 7.6 & 8 \\
Number of cyles triggering "failure" of the pile & 23 & 36
\end{tabular}

Table 5: Numerical and experimental results for a cyclic loading of a pile. "Failure" of the pile is defined for a vertical displacement of the pipe equal to the tenth of its diameter.

They are closely related to the internal state of the volume element of soil or of the interface respectively. The influence of density, mean pressure and anisotropy of contact directions within the cohesionless material which are nowadays quite well established, were emphasized. A unique set of model parameters is used though large changes with the internal structure are likely to occur throughout cyclic loadings. CJS model for the volume element was deeply enhanced in this regard and a similar interface model denoted CJSi was derived. The introduction of a state parameter proposed by [54] with reference to the critical state line allows to encompass the effects of density and mean pressure for soil and interfaces. In the case of the volume element of soil, a kinematic hardening of the yield surface is required to take into account the effects of induced anisotropy on the behaviour of the material.

A multi-scale validation of CJS and CJSi model was provided using experiments involving Fontainebleau sand. After the calibration of CJS model parameters, monotonic triaxial experiments with different initial states including density and mean pressure could have been predicted with a good accuracy. Direct shear tests of an interface between Fontainebleau sand and a rough structure could have been reproduced for two density states and throughout two reversals of loading direction. Finally, a boundary value problem was studied on the basis of these two constitutive models. It was part of a benchmark where centrifuge tests on an axially loaded pile were performed. The simulations of the monotonic and cyclic loadings on the pile were predicted with fairly good accuracy validating the constitutive models presented in this work.

\section{Acknowledgements}

This work was supported by the French programm ANR-07-PGCU-0005 SOLCYP funded by the National Agency of Research (ANR). Partners from Navier laboratory performed the trixial experiments on Fontainebleau sand. The authors thank especially our partners from 3SR laboratory (S. Pra-Ai, M. Boulon) for the interface test data, and our partners from IFFSTAR (L. Thorel) for the test data on pile. The authors also express their gratitude to Y. Bagagli whose PhD Thesis [78] served as starting point for this work; and B. Cambou and F. Darve for their kind attention about this work.

[1] P. V. Lade, J. M. Duncan, Elasto-plastic stress-strain theory for cohesion- 
less soil, Journal of the Geotechnical Engineering Division 101 (10) (1975) $1037-1053$.

[2] Y. F. Dafalias, L. R. Herrmann, A bounding surface soil plasticity model, in: Proc. of Int. Symposium on Soils under Cyclic and Transient Loading, 1980, pp. 335-343.

[3] D. Kolymbas, A rate-dependent constitutive equation for soils, Mechanics Research Communications 4 (6) (1977) 367-372.

[4] R. Chambon, B. Renoud-Lias, Incremental non-linear stress-strain relationship for soil and integration by finite element method, in: Proc. 3rd Numer. Meth. in Geomechanics, 1979, pp. 405-413.

[5] F. Darve, Une loi rhéologique incrémentale non-linéaire pour les solides, Mechanics Research Communications 7 (4) (1980) 205-212.

[6] R. Chambon, J. Desrues, W. Hammad, R. Charlier, Cloe, a new rate-type constitutive model for geomaterials theoretical basis and implementation, International Journal for Numerical and Analytical Methods in Geomechanics 18 (4) (1994) 253-278. doi:10.1002/nag.1610180404.

[7] F. Darve, E. Flavigny, M. Méghachou, Yield surfaces and principle of superposition revisited by incrementally non-linear constitutive relations, Int. Journal Plasticity 11 (8) (1995) 927-948.

[8] Y. Dafalias, Bounding surface plasticity. i: Mathematical foundation and hypoplasticity, Journal of Engineering Mechanics 112 (9) (1986) 966-987. doi:10.1061/(ASCE)0733-9399(1986)112:9(966).

[9] A. S. Saada, G. Bianchini, Constitutive equations for granular non-cohesive soils, in: International Workshop on Constitutive Equations for Granular Non-cohesive Soils (1987: Cleveland, Ohio), AA Balkema, 1989.

[10] H. D. Benedetto, O. Hameury, G. B. Cazacliu, Incremental constitutive law for sand: Anisotropic and cyclic effects, in: Earthquake Engineering, Tenth World Conference, Balkema, 1992.

[11] M. Mohkam, Contribution à l'étude expérimentale et théorique du comportement des sables sous chargements cycliques, Ph.D. thesis, Université Scientifique et Médicale \& Institut National Polytechnique de Grenoble (1983).

[12] R. P. Ray, R. D. Woods, Modulus and damping due to non uniform and variable cyclic loading, Journal of Geotechnical Engineering, ASCE 114 (8) (1988) 861-876.

[13] H. Shahnazari, I. Towhata, Torsion shear tests on cyclic stress-dilatancy relationship of sand, Soils and Foundations 42 (1) (2002) 105-119. 
[14] T. Wichtmann, A. Niemunis, T. Triantafyllidis, Strain accumulation in sand due to cyclic loading: Drained triaxial tests, Soil Dynamics and Earthquake Engineering 25 (12) (2005) 967-979.

[15] K. H. Roscoe, A. N. Schofield, C. P. Wroth, On the yielding of soils, Géotechnique 8 (1958) 22-53(31).

[16] R. Verdugo, K. Ishihara, The steady state of sandy soils, Soils and foundations 36 (2) (1996) 81-91.

[17] W. Wu, E. Bauer, D. Kolymbas, Hypoplastic constitutive model with critical state for granular materials, Mechanics of Materials 23 (1) (1996) 45 69. doi:10.1016/0167-6636(96)00006-3.

[18] E. Bauer, Conditions for embedding casagrande's critical states into hypoplasticity, Mechanics of Cohesive-frictional Materials 5 (2) (2000) 125-148. doi:10.1002/(SICI)1099-1484(200002)5:2<125::AIDCFM85 $>3.0 . \mathrm{CO} ; 2-0$.

[19] M. T. Manzari, Y. F. Dafalias, A critical state two-surface plasticity model for sands, Géotechnique 47 (1997) 255-272(17).

[20] X. S. Li, Y. F. Dafalias, Dilatancy for cohesionless soils, Géotechnique 50 (2000) 449-460.

[21] T. Doanh, Z. Finge, S. Boucq, Effects of previous deviatoric strain histories on the undrained behaviour of hostun $\mathrm{rf}$ loose sand, Geotechnical and Geological Engineering (2010) 1-16doi:10.1007/s10706-011-9487-9.

[22] R. G. Wan, P. J. Guo, Effect of microstructure on undrained behaviour of sands, Canadian Geotechnical Journal 38 (1) (2001) 16-28. doi:10.1139/cgj38-1-16.

[23] A. Gajo, D. Bigoni, A model for stress and plastic strain induced nonlinear, hyperelastic anisotropy in soils, International Journal for Numerical and Analytical Methods in Geomechanics 32 (7) (2008) 833-861. doi:10.1002/nag.648.

[24] J. M. Pestana, A. J. Whittle, Formulation of a unified constitutive model for clays and sands, International Journal for Numerical and Analytical Methods in Geomechanics 23 (12) (1999) 1215-1243. doi:10.1002/(SICI)10969853(199910)23:12<1215::AID-NAG29>3.0.CO;2-F.

[25] R. G. Wan, P. J. Guo, Drained cyclic behavior of sand with fabric dependence, Journal of Engineering Mechanics 127 (11) (2001) 1106-1116. doi:10.1061/(ASCE)0733-9399(2001)127:11(1106).

[26] F. Jafarzadeh, H. Javaheri, T. Sadek, D. M. Wood, Simulation of anisotropic deviatoric response of hostun sand in true triaxial tests, Computers and Geotechnics 35 (5) (2008) 703 - 718. doi:10.1016/j.compgeo.2007.11.005. 
[27] B. Cambou, K. Jafari, Modèle de comportement des sols non cohérents, Revue française de Géotechnique 44 (1988) 43-55.

[28] B. Cambou, J. Lanier, Induced anisotropy in cohesionless soil: Experiments and modelling, Computers and Geotechnics 6 (4) (1988) 291-311. doi:10.1016/0266-352X(88)90071-7.

[29] K. Elamrani, Contributions à la validation du modèle cjs pour les matériaux granulaires, Ph.D. thesis, École Centrale de Lyon (1992).

[30] M. P. Luong, Phénomènes cycliques dans les sols pulvérulents, Revue française de géotechnique 10 (1980) 39-53.

[31] T. B. Pradhan, F. Tatsuoka, Y. Sato, Experimental stress-dilatancy relations of sand subjected to cyclic loading, Soils and Foundations 29 (1) (1989) 45-64.

[32] F. Tatsuoka, T. Masuda, M. Siddiquee, J. Koseki, Modeling the stressstrain relations of sand in cyclic plane strain loading, Journal of Geotechnical and Geoenvironmental Engineering 129 (5) (2003) 450-467. doi:10.1061/(ASCE)1090-0241(2003)129:6(450).

[33] H. Matsuoka, T. Nakai, Stress-deformation and strength characteristics of soil under three different principal stresses, Proc. Japan Soc. Civil Engrs. 232 (1974) 59-70.

[34] C. Thornton, Numerical simulations of deviatoric shear deformation of granular media, Géotechnique 50 (1) (2000) 43-53. doi:10.1680/geot.2000.50.1.43.

[35] F. Calvetti, G. Viggiani, C. Tamagnini, A numerical investigation of the incremental behavior of granular soils, Rivista Italiana di Geotecnica 3 (2003) 11-29.

[36] T.-T. Ng, Behavior of gravity deposited granular material under different stress paths, Canadian Geotechnical Journal 42 (6) (2005) 1644-1655.

[37] J. Jiang, S. Pietruszczak, Convexity of yield loci for pressure sensitive materials, Computers and Geotechnics 5 (1) (1988) $51-63$.

[38] B. Halphen, Q. Son Nguyen, Sur les matériaux standard généralisés, Journal de Mécanique 14 (1975) 39-63.

[39] K. Ishihara, F. Tatsuoka, S. Yasuda, Undrained deformation and liquefaction of sand under cyclic stress, Soils and Foundations 15 (1) (1975) 29-44.

[40] J. Biarez, P. Y. Hicher, Elementary mechanics of soil behaviour Saturated remoulded sois, A. A. Balkema, Rotterdam, 1994.

[41] B. O. Hardin, F. E. Richart, Elastic wave velocities in granular soils, Journal of Soil Mechanics \& Foundations Div 89 (1963) 33-65. 
[42] T. Hueckel, G. Maier, Incremental boundary value problems in the presence of coupling of elastic and plastic deformations: A rock mechanics oriented theory, International Journal of Solids and Structures 13 (1) (1977) 1 - 15. doi:10.1016/0020-7683(77)90087-7.

[43] G. Houlsby, The use of a variable shear modulus in elastic-plastic models for clays, Computers and Geotechnics 1 (1) (1985) 3 - 13.

[44] I. F. Collins, G. T. Houlsby, Application of thermomechanical principles to the modelling of geotechnical materials, Proceedings of the Royal Society of London. Series A: Mathematical, Physical and Engineering Sciences 453 (1964) (1997) 1975-2001. doi:10.1098/rspa.1997.0107.

[45] M. Zytynski, M. F. Randolph, R. Nova, C. P. Wroth, On modelling the unloading-reloading behaviour of soils, International Journal for numerical and analytical methods in geomechanics 2 (1) (1978) 87-93. doi:10.1002/nag.1610020107.

[46] A. Niemunis, M. Cudny, On hyperelasticity for clays, Computers and Geotechnics 23 (4) (1998) 221 - 236. doi:10.1016/S0266-352X(98)000226 .

[47] R. I. Borja, C. Tamagnini, Cam-clay plasticity part iii: Extension of the infinitesimal model to include finite strains, Computer Methods in Applied Mechanics and Engineering 155 (1-2) (1998) 73 - 95. doi:10.1016/S00457825(97)00141-2.

[48] R. Nova, R. Castellanza, C. Tamagnini, A constitutive model for bonded geomaterials subject to mechanical and/or chemical degradation, International Journal for Numerical and Analytical Methods in Geomechanics 27 (9) (2003) 705-732. doi:10.1002/nag.294.

[49] Y.-S. Kim, F. Tatsuoka, K. Ochi, Deformation characteristics at small strains of sedimentary soft rocks by triaxial compression tests, Géotechnique 44 (1994) 461-478.

[50] P.-Y. Hicher, Elastic properties of soils, Journal of Geotechnical Engineering 122 (8) (1996) 641-648. doi:10.1061/(ASCE)07339410(1996)122:8(641).

[51] B. Loret, On the choice of elastic parameters for sand, International Journal for Numerical and Analytical Methods in Geomechanics 9 (3) (1985) 285292. doi:10.1002/nag.1610090308.

[52] A. Schofield, P. Wroth, Critical state soil mechanics, Mc Graw - Hill, 1968.

[53] C. Nouguier-Lehon, B. Cambou, E. Vincens, Influence of particle shape and angularity on the behaviour of granular materials: a numerical analysis, International Journal for Numerical and Analytical Methods in Geomechanics 27 (2003) 1207-1226. 
[54] K. Been, M. G. Jefferies, A state parameter for sands, Géotechnique 35 (2) (1985) 99-112.

[55] D. Negussey, W. K. D. Wijewickreme, Y. P. Vaid, Constant-volume friction angle of granular materials, Canadian Geotechnical Journal 25 (1) (1988) 50-55. doi:10.1139/t88-006.

[56] K. L. Lee, H. B. Seed, Drained strength characteristics of sands, Journal of Soil Mechanics \& Foundations Div 93 (SM6) (1967) 117 - 141.

[57] M. D. Bolton, The strength and dilatancy of sands, Géotechnique 36 (1) (1986) 65-78.

[58] Y. Yunus, E. Vincens, B. Cambou, Numerical local analysis of relevant internal variables for constitutive modelling of granular materials, International Journal for numerical and analytical methods in geomechanics 34 (11) (2010) 1101-1123. doi:10.1002/nag.845.

[59] E. Vincens, C. Nouguier-Lehon, The characteristic state, European Journal of Environmental and Civil Engineering 16 (7) (2012) 777-794. doi:10.1080/19648189.2012.671057.

[60] F. Calvetti, G. Combe, J. Lanier, Experimental micromechanical analysis of a $2 \mathrm{~d}$ granular material: relation between structure evolution and loading path, Mechanics of Cohesive-Frictional Materials 2 (1997) 121-163.

[61] S. Luding, Micro-macro transition for anisotropic, frictional granular packings, International Journal of Solids and Structures 41 (2004) 5821-5836.

[62] J. Biarez, K. Wiendick, La comparaison qualitative entre l'anisotropie mécanique et l'anisotropie de structure des milieux pulvérulents, C. R. à l'Académie des Sciences 256 (1963) 1217-1220.

[63] M. Oda, S. Nemat-Nasser, J. Konishi, Stress-induced anisotropy in granular masses, Soils and Foundations 25 (3) (1985) 85-97.

[64] J. Fonseca, C. O'Sullivan, M. Coop, P. Lee, Quantifying the evolution of soil fabric during shearing using directional parameters, Géotechnique 63 (2013) 487-499.

[65] E. Vincens, Y. Yunus, B. Cambou, Modelling of volume change in granular materials in relation to their internal state, C. R. Mecanique 338 (10-11) (2010) 615-626. doi:10.1016/j.crme.2010.10.002.

[66] I. Shahrour, F. Rezaie, An elastoplastic constitutive relation for the soilstructure interface under cyclic loading, Computers and Geotechnics 21 (1) (1997) 21 - 39. doi:10.1016/S0266-352X(97)00001-3.

[67] V. D. Gennaro, R. Frank, Elasto-plastic analysis of the interface behaviour between granular media and structure, Computers and Geotechnics 29 (7) (2002) 547 - 572. doi:10.1016/S0266-352X(02)00010-1. 
[68] G. Mortara, M. Boulon, V. N. Ghionna, A 2-d constitutive model for cyclic interface behaviour, International Journal for Numerical and Analytical Methods in Geomechanics 26 (11) (2002) 1071-1096. doi:10.1002/nag.236.

[69] H. Liu, E. Song, H. I. Ling, Constitutive modeling of soilstructure interface through the concept of critical state soil mechanics, Mechanics Research Communications 33 (4) (2006) 515 - 531. doi:10.1016/j.mechrescom.2006.01.002.

[70] H. Liu, H. I. Ling, Constitutive description of interface behavior including cyclic loading and particle breakage within the framework of critical state soil mechanics, International Journal for Numerical and Analytical Methods in Geomechanics 32 (12) (2008) 1495-1514. doi:10.1002/nag.682.

[71] L. Hu, J. L. Pu, Application of damage model for soil-structure interface, Computers and Geotechnics 30 (2) (2003) 165 - 183. doi:10.1016/S0266$352 \mathrm{X}(02) 00059-9$.

[72] V. Fioravante, On the shaft friction modelling of non-displacement piles in sand, Soils and Foundations 42 (2002) 23-33. doi:10.3208/sandf.42.2_23.

[73] E. Evgin, K. Fakharian, Effect of stress paths on the behaviour of sand steel interfaces, Canadian Geotechnical Journal 33 (6) (1996) 853-865.

[74] T. A. Oumarou, E. Evgin, Cyclic behaviour of a sand - steel plate interface, Canadian Geotechnical Journal 42 (6) (2005) 1695-1704. doi:10.1139/t05083.

[75] J. T. DeJong, M. F. Randolph, D. J. White, Interface load transfer degradation during cyclic loading : a microscale investigation, Soils and Foundations 43 (4) (2003) 81-93.

[76] Z. Yang, R. Jardine, B. Zhu, P. Foray, C. Tsuha, Sand grain crushing and interface shearing during displacement pile installation in sand, Géotechnique 60 (6) (2010) 469-482.

[77] T. Y. K. Ho, R. J. Jardine, N. Anh-Minh, Large-displacement interface shear between steel and granular media, Géotechnique 61 (3) (2011) 221234. doi:10.1680/geot.8.P.086.

[78] Y. Bagagli, Modélisation cyclique des sols et interfaces sol/structure, Ph.D. thesis, École Centrale de Lyon (2011).

[79] S. C. D'Aguiar, A. Modaressi-Farahmand-Razavi, J. A. dos Santos, F. Lopez-Caballero, Elastoplastic constitutive modelling of soil-structure interfaces under monotonic and cyclic loading, Computers and Geotechnics 38 (4) (2011) 430 - 447. doi:10.1016/j.compgeo.2011.02.006. 
[80] D. J.-C. Andria-Ntoanina I., Canou J., Caractérisation mécanique du sable de fontainebleau ne34 à l'appareil triaxial sous cisaillement monotone, Tech. rep., Report of SOLCYP project, CERMES team, Navier Laboratory (ENPC / IFSTTAR / CNRS) (2010).

[81] R. Saim, Des comportements repères des grains sans colle à un exemple de sol réel, Ph.D. thesis, École Centrale Paris (1997).

[82] AFNOR, Sols : reconnaissance et essais - Détermination des masses volumiques minimale et maximale des sols non cohérents, p94-059 (Novembre 2000).

[83] S. Pra-Ai, Behaviour of soil-structure interfaces subjected to a large number of cycles. application to piles, Ph.D. thesis, Université de Grenoble (2013). URL http://tel.archives-ouvertes.fr

[84] A. Guefrech, G. Rault, N. Chenaf, L. Thorel, J. Garnier, A. Puech, Stability of cast in place piles in sand under axial cyclic loading, in: 7th International Conference Offshore Site investigation and Geotechnics, London, 2012, pp. 329-334. 